\title{
Transition From Alcohol to Other Drugs Among Adolescents in Taiwan: The First Drinking Context Matters*
}

\author{
CHUAN-YU CHEN, PH.D., ${ }^{\dagger}$ GUNG-MONG TANG, M.S., SU-LING HUANG, M.S., ${ }^{\dagger}$ CHING-MEI LEE, PH.D., ${ }^{\dagger}$ \\ CHIH-YIN LEW-TING, PH.D., ${ }^{\dagger}$ CHUHSING KATE HSIAO, PH.D., ${ }^{\dagger}$ DUAN-RUNG CHEN, PH.D., ${ }^{\dagger}$ AND WEI J. CHEN, M.D., SC.D. ${ }^{\dagger}$
}

Institute of Epidemiology, College of Public Health, National Taiwan University, 17 Xu-Zhou Road, Taipei, 100, Taiwan

\begin{abstract}
Objective: This study examined the extent to which youthful alcohol consumption and the initiation of tobacco, betel nut, and other illegal drugs may differ by their first drinking context in Taiwan-a society with social norms that are more tolerant of underage drinking. Method: In 2004, in a nationally representative sample of 11,943 school-attending youth ages $15-18$, information pertaining to sociodemographic characteristics, problem behaviors, lifetime experiences of alcohol, tobacco, betel nut, and illegal drugs, as well as psychoactive, drug-specific age of initiation, context at first use, average frequency, and recency of use, was assessed by anonymous questionnaires. Results: Youth who had their first alcoholic beverages in enter-
\end{abstract}

tainment settings or at friends' houses were more likely to become frequent drinkers. After adjustment for socioeconomic background and problem behaviors, having had the first drink in entertainment settings was associated with a faster progression into the initiation of illegal drugs (hazard ratio $[\mathrm{HR}]=2.5,95 \%$ confidence interval $[\mathrm{CI}]: 1.5-4.0$ ) and betel nut (HR $=1.5,95 \% \mathrm{CI}: 1.1-2.1)$. Conclusions: Youthful drinking pattern and transition from alcohol to betel nut and illegal drugs may vary modestly by the first drinking context. This context may be recognized as a proxy variable to identify youth at a higher risk for alcohol and other drug problems and to devise context-based educational or prevention programs. (J. Stud. Alcohol Drugs 69: 378-387, 2008)
A LCOHOL USE AND RELATED PROBLEMS in adolescence continue to cause public health concern in many industrialized countries (Bonnie and O'Connell, 2004; O'Malley et al., 1998). A number of studies have shown that early-onset alcohol initiation is adverse not only in relation to severe alcohol clinical problems but also is associated with increased risk-taking or health-comprising behaviors, such as driving under the influence, unprotected sexual behaviors, and violent behaviors (Bonnie and O'Connell, 2004; Shore and Spicer, 2004; So et al., 2005). Moreover, epidemiological evidence from the United States, France, and other parts of the world indicates that the engagement of alcoholic beverage and tobacco, so-called gateway drugs, may significantly elevate one's subsequent risks of exposure opportunity and actual use of illegal drugs (Adler and Kandel, 1981; Golub and Johnson, 1994; Kandel et al., 1992; Wagner and Anthony, 2002).

Received: June 13, 2007. Revision: January 5, 2008.

*This research was supported by grants DOH93-NNB-1012, DOH94NNB-1014, and DOH95-NNB-1012 from the Department of Health, Taiwan, to Wei J. Chen and by grants MD094PP02 and MD096PP04 from the National Health Research Institute, Taiwan, to Chuan-Yu Chen.

Correspondence may be sent to Wei J. Chen at the above address or via email at: wjchen@ntu.edu.tw. Wei J. Chen is also with the Department of Public Health, College of Public Health, National Taiwan University, Taipei, Taiwan, and the Department of Psychiatry, College of Medicine and National Taiwan University Hospital, National Taiwan University, Taipei. ChuanYu Chen is with the Division of Mental Health and Substance Abuse Re-
One of the most important aspects of underage drug experiences is that initiation, consumption amount, or problems are largely context dependent, which is particularly true for alcohol drinking (Kairouz et al., 2002; Knibbe, 1998; Orcutt, 1975). For example, undergraduate students were consistently found to drink more in bars and group settings, and heavy episodic drinking tends to occur while youth socialize with friends or at parties (Clapp et al., 2000; Demers et al., 2002; Harford et al., 1983; Rossow, 1996). Some researchers have extended this line of research by focusing on the context of first drink, given that younger age of initiation is a stronger predictor of subsequent problem drinking (Bonnie and O'Connell, 2004). On the basis of community-dwelling youth prospectively followed up from adolescence to young adulthood, Warner and White (2003) found that the risk of problem drinking was most salient for the subgroup of youth characterized by

search, National Health Research Institutes, Taipei, Taiwan; the Department of Public Health, College of Public Health, National Taiwan University, Taipei, Taiwan; and the Institute of Public Health, School of Medicine, National Yang Ming University, Taipei, Taiwan. Su-Ling Huang is with the Division of Mental Health and Substance Abuse Research, National Health Research Institutes, Taipei, Taiwan. Ching-Mei Lee is with the Department of Health Education, National Normal Taiwan University, Taipei, Taiwan. Chih-Yin Lew-Ting and Chuhsing Kate Hsiao are with the Department of Public Health, College of Public Health, National Taiwan University, Taipei, Taiwan. DuanRung Chen is with the Institute of Healthcare Organization Administration, College of Public Health, National Taiwan University, Taipei, Taiwan. 
early-onset alcohol initiation in the context outside family gatherings. Despite this body of work, current evidence characterizing the effects of drinking context or situation is mainly derived from Western populations (Demers et al., 2002; Harford et al., 1983; K nibbe, 1998). Few studies have examined such links in countries or societies with different norms, regulations, and enforcement practice toward underage drinking.

Alcoholic beverages have been an integral part of Chinese culture for millennia (Cochrane et al., 2003; Hao et al., 2005; Y ang, 2002). In addition to its significant roles in traditional medicine and food preparation, alcohol has been considered as one of the indispensable elements in promoting cheerfulness or facilitating interactions at family reunions, weddings, birthday parties, and business activities. Although, by law, minors are not allowed to drink or purchase alcoholic beverages, youth access to alcoholic products is utterly effortless. However, Taiwan has witnessed several remarkable transformations regarding alcohol, tobacco, betel nut, and other illegal drug problems. One transformation involves an increase of alcohol and tobacco availability to youth and a decline in the initiation age of tobacco and betel nut use as a consequence, in part, of the trade liberalization and lowered custom tariffs on imported tobacco and alcoholic beverages ( $L$ in et al., 2003; $W$ en et al., 2005a,b). A nother transformation involves the upsurge in availability and diversity of illegal drugs, particularly methamphetamines, Ecstasy, and heroin (Chiang et al., 2006; Chou et al., 2006; Y en et al., 2007).

In a culture in which most drinkers have had their first drinks as early as in childhood, alcohol initiation per se may not be a pivotal factor in predicting subsequent drug experiences. With an intention to identify possible heterogeneity among alcohol-experienced youth, this research hypothesized that first drinking context would help to predict youthful differential progression to the initiation of other psychoactive drug involvement. Building on a recently conducted school survey with nationally representative youth samples in Taiwan, the aims of the present study are (1) to examine the extent to which youth frequency of alcohol consumption may differ by first drinking context and (2) to probe possible first drinking context-related differences in progression from alcohol into tobacco, betel nut, and other illegal drugs among youth ages 15-18.

\section{Method}

Study sample

Data for this study are generated from the $2004 \mathrm{Na}$ tional Survey of Illegal Drug Use among Adolescents (NSIDA) in Taiwan. The NSIDA is a cross-sectional survey of behavioral and psychological problems, drug expe- riences, and life events of school-attending youth ages 12 18. In brief, during the 2004-2005 academic year, the NSIDA team drew nationally representative samples from schools via multistage sampling procedures. A sampling strategy was developed to cover middle school and two types of high schools (i.e., senior high and vocational/technical high schools) in seven living regions of Taiwan, defined by geographic characteristics, urbanicity level, and population composition (Chen et al., 2006). Considering a relatively lower prevalence of illegal drug experiences in middle school ages in Taiwan, the present study focuses primarily on youth (ages 15-18) attending senior high and vocational/technical high schools. On the basis of aggregate lists obtained from the M inistry of Education, a total of 88 high schools were selected. In the case in which the school directors of two vocational high schools were unwilling to allow participation of their schools, a replacement school of the same type was selected from the same living region. Within each high school, two classes were randomly selected from Grades 10 and 12 . All the students in the sampled classes were eligible to participate in the survey. The participation rate was $98.8 \%$ at the high-school level, $98.2 \%$ at the 10 th-grade level, $79.2 \%$ at the 12 thgrade level, and $90.1 \%$ at the individual level.

A total of 12,791 high school-attending youth respondents completed anonymous questionnaires for the NSIDA. To focus on high school-age adolescent drug experiences, the present study excluded the following: (1) 9 respondents who reported using a fake drug; (2) 77 respondents whose responses were missing in all drug items; and (3) 762 respondents whose questionnaires indicated an age younger than 12 or older than 18, resulting in the final analytic sample of 11,943 respondents.

\section{Data collection}

Data collection was primarily conducted during regular class time, and one or two research assistants were present to promote trust and to ensure confidentiality. For high school-age youth, survey assessments were completed by paper-and-pencil self-administration, with a mean duration of approximately 20-30 minutes. For each potential participant, a fixed sequence of standardized preworded and precoded survey questions was designed to obtain information regarding his/her sociodemographic background, problem behaviors, drug-associated experiences, life events, and internal izing/externalizing behaviors. As the assessment was completed, each participant received stationery incentives from the NSIDA team equal to no more than $20 \mathrm{New}$ Taiwan Dollars ( 1 United States Dollar $\cong 30 \mathrm{New}$ Taiwan Dollars). The study was reviewed and approved by the institutional review board of the College of Public Health at the $\mathrm{N}$ ational Taiwan University. 


\section{Definition of study variables}

The NSIDA assessed lifetime psychoactive drug experiences for alcohol, tobacco, betel nut, and nine other types of psychoactive substances, including Ecstasy (i.e., 3,4methylenedioxymethamphetamine [MDMA]), glue, methamphetamine, ketamine, flunitrazepam (also known as FM 2), marijuana, heroin or morphine, phencycyclidine $(P C P)$, and gamma-hydroxybutyrate (GHB). For convenience, these nine types of psychoactive substances were denoted as illegal drugs in this study. B etel nut is one of the most commonly consumed psychoactive drugs in South and Pacific Asian countries (Changrani and Gany, 2005; Chu, 2001). Given that marijuana is not widely available in Taiwan and the majority of illegal drug users have chewed betel nut earlier in their lives, it has been hypothesized that - in the stage theory - betel nut has played a role simiIar to marijuana (K andel, 1975; W en et al., 2005b). Those individuals who reported having used particular psychoactive drugs at least once were subsequently asked information regarding drug-specific age at first use, context at first use, average frequency of consumption, and recency of use. For illegal drugs, we coded the initiation age as one's earliest age to start any of nine illegal drugs. According to the self-reported context of first alcohol use, alcohol-experienced youth were further regrouped into four main categories defined by (1) family ( $n=2,069)$, (2) friends' houses ( $n=684)$, (3) entertainment places (e.g., pubs, karaoke lounges; $n=992$ ), and (4) other settings (e.g., schools, parks; $n=1,139)$. F requent al cohol drinker was determined if one's alcohol was consumed at one or more occasions per month. Having started alcohol use before age 12 was defined as early onset. Recent alcohol use was defined as having had alcoholic beverages at least once in the preceding 30 days before the assessment.

Other variables potentially confounding the associations linking alcohol drinking context with tobacco, betel nut, and illegal drug initiation included sociodemographics (e.g., gender, family structure, and weekly allowance), living with family, and problem behaviors. In Taiwan, high school-age adolescents may move out of the home to attend schools that are beyond commuting distance from their homes. In this particular scenario, youth often live in school dorms or rental housing with either same-school students or friends. In this analysis, not living with family served as a proxy measure for lower levels of parental supervision. In addition, because the present study was intended to distinguish the initiation time of problem behaviors and substance use, only those behavioral items with information of onset age were included (e.g., truancy and running away from home). A more detailed assessment of youth emotional or behavioral problems using the Y outh Self-Report (A chenbach, 1995; Chen et al., 2008) was not included for analysis. Features of problem behaviors in adolescence assessed in this study covered lifetime experiences of truancy and running away from home, age at first occurrence, and cumulative frequency.

\section{Data analysis}

Because of the multistage probability sampling procedures used in the NSIDA, standard survey analysis procedures were first used to compare the distribution of sociodemographic characteristics and lifetime drug experiences for four subgroups, defined by the context of first alcoholic beverage with that of the alcohol naive. Odds ratios and $95 \%$ confidence intervals ( $\mathrm{Cls}$ ) were derived by taking into consideration the sampling weights (e.g., to compensate for variation in sample selection probability) and the complex sampling design via the Taylor series method (Lee and Forthofer, 2005). M ultivariate multinomial logistic regression models were used to estimate the association linking early-onset problem and alcohol-using pattern with the first drinking context and with the statistical adjustment for an array of sociodemographic characteristics.

$K$ aplan-M eier analyses were performed to estimate the cumulative hazard of drug initiation yearly from the age of starting alcohol use by the first drinking context. Lifetime estimates of alcohol use among cigarette smoking-, betel nut-, and illegal drug-experienced youth were $77 \%, 88 \%$, and $89 \%$, respectively. In nearly $60 \%, 77 \%$, and $93 \%$ of the cases, alcohol had been used either in the same year or before first use of tobacco, betel nut, and illegal drugs, respectively. To assess whether the instantaneous risk of starting use of tobacco, betel nut, and illegal drugs varies by the first drinking context, the semiparametric Cox proportional hazards model was implemented to estimate context-associated hazard ratios (HRs) and $95 \% \mathrm{Cls}$. The first model examined the effect of first drinking context, with adjustment for gender, family, weekly allowance, and covariates of time-varying characteristics (i.e., age of first truancy, age when first running away from home), and variables that can be potentially influenced by alcohol involvement (e.g., vocational school attendance). To consider developmental, stage-associated variation in the risk of psychoactive drug initiation, analyses were repeated for the subsample defined by alcohol onset later than age 12; results were denoted as Model 2 ( $n=3,540)$. All statistical analyses were conducted with STATA, Version 8.0 (StataCorp LP, College Station, TX).

\section{Results}

Distribution of sociodemographic background and drug experiences among school-attending youth stratified by alcohol experiences is shown in Table 1. M ore than $40 \%$ of youth had tried alcohol at least once in their lifetimes $(n=$ $4,884)$, and most first drinks took place at home $(42.4 \%)$ 


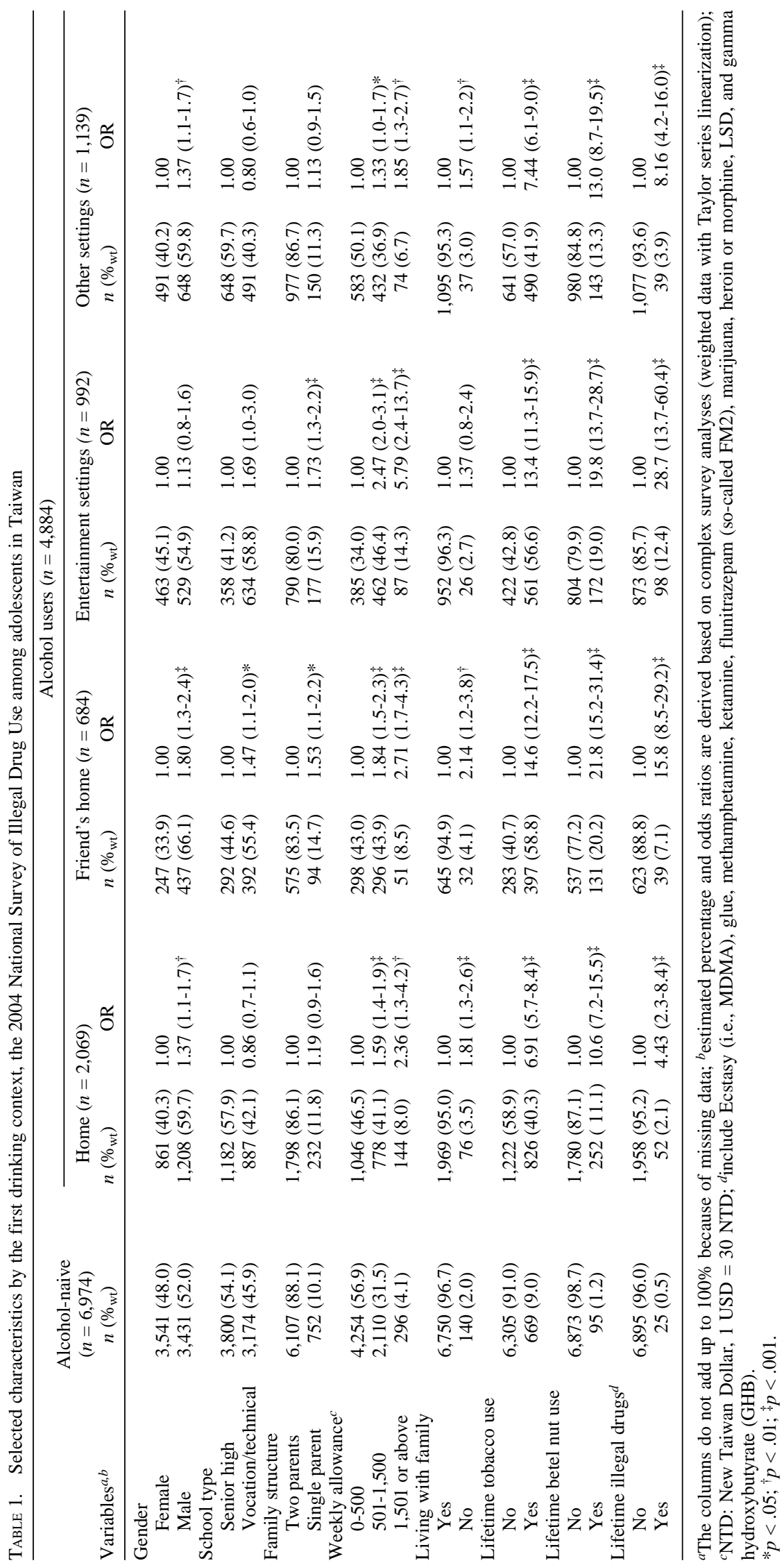


and in entertainment settings (20.3\%). Compared with their alcohol-naive peers, alcohol-experienced youth were more likely to be male, attend vocational/technical schools, come from a single-parent household, have more weekly disposable allowance, and not reside currently with their families. Notably, an estimated $2 \%-13 \%$ of alcohol-experienced youth had started use of illegal drugs, which was nearly 4fold to 29-fold greater likelihood than their alcohol-naive counterparts.

Results of multivariate complex survey analyses showed that alcohol-experienced youth in the four subgroups endorsed similar occurrence of early-onset problem behaviors, such as running away from home and truancy at primary school ages (Table 2). However, alcohol-drinking pattern differed substantially by the first drinking context. For example, when compared with youth who had their drinks at family occasions, youth who had their first drinks in entertainment settings and at friends' houses tended to start alcohol use at ages later than 12. Moreover, an estimated two-fold to six-fold risk of higher frequency of alcohol consumption was found associated with having first drinks in situations other than at family occasions (e.g., entertainment settings for monthly drinking; adjusted odds ratio $=6.09,95 \% \mathrm{Cl}=4.8-7.7, \mathrm{p}<.001)$.
Figure 1 shows the estimated cumulative hazard of tobacco, betel nut, and illegal drug initiation by the context of first alcohol drinking. In general, youth who had their first alcoholic beverage on occasions such as entertainment settings or at friends' houses were more likely to start use of betel nut and illegal drugs than those in family occasions. However, the observed first drinking context-related risk of drug initiation seems different across drug category (Table 3). Crude HR estimates indicate that youth who had their first alcoholic drink in entertainment settings were at twofold risk to start betel nut chewing and at fivefold risk to start use of illegal drugs, as compared with those whose first drink occurred at family occasions. When all covariates were included in Model 1, the contextual differences in the hazard of tobacco initiation were no longer statistically significant. N evertheless, despite further attenuation, the HRS for betel nut and illegal drugs remained significant for the situations such as entertainment settings (adjusted $H R$ [aH R ] for betel nut $=1.45,95 \% \mathrm{Cl}$ : 1.1-2.0; aHR for illegal drugs $=2.70,95 \% \mathrm{Cl}: 1.8-4.1$ ) and friends' houses (aHR for illegal drugs $=1.73,95 \% \mathrm{Cl}: 1.1-2.8$ ). Similar HR estimates were obtained as we repeated the analyses exclusively for youth taking their first drink later than age 12 (M odel 2 in Table 3).

TABLE 2. Estimated associations between first drinking context with early-onset problem behaviors and alcohol experiences in the $2004 \mathrm{National}$ Survey of Illegal Drug Use among adolescents in Taiwan

\begin{tabular}{|c|c|c|c|c|c|c|c|c|}
\hline \multirow[b]{3}{*}{ V ariables ${ }^{a, b, c}$} & \multirow{3}{*}{$\begin{array}{c}\text { A lcohol naive } \\
(n=6,974) \\
n\left(\%_{w t}\right)\end{array}$} & \multicolumn{7}{|c|}{ Alcohol users $(n=4,884)$} \\
\hline & & \multirow{2}{*}{$\begin{array}{c}\text { Home } \\
(n=2,069) \\
n\left(\%_{w t}\right)\end{array}$} & \multicolumn{2}{|c|}{ Friend's house $(n=684)$} & \multicolumn{2}{|c|}{ Entertainment settings ( $n=992$ ) } & \multicolumn{2}{|c|}{ Other settings ( $n=1,139$ ) } \\
\hline & & & $\mathrm{n}\left(\%_{\mathrm{wt}}\right)$ & AOR & $\mathrm{n}\left(\%_{\mathrm{wt}}\right)$ & $A O R$ & $\mathrm{n}\left(\%_{\mathrm{wt}}\right)$ & AOR \\
\hline No & $6,691(96.2)$ & $1,898(91.9)$ & $634(93.6)$ & 1.00 & $899(88.4)$ & 1.00 & $1,044(91.2)$ & 1.00 \\
\hline Yes & $234(3.3)$ & $162(7.5)$ & $50(6.4)$ & $0.75(0.5-1.2)$ & $90(10.7)$ & $1.49(0.8-2.6)$ & $88(8.3)$ & $1.10(0.6-2.0)$ \\
\hline \multicolumn{9}{|l|}{ Early-onset runawayd } \\
\hline \multicolumn{9}{|l|}{ Early-onset tobacco use ${ }^{d}$} \\
\hline No & $6,828(98.1)$ & $1,873(91.2)$ & $628(91.6)$ & 1.00 & $912(94.0)$ & 1.00 & $1,034(92.8)$ & 1.00 \\
\hline Yes & $146(1.9)$ & $196(8.8)$ & $56(8.4)$ & $0.88(0.6-1.4)$ & $80(6.0)$ & $0.65(0.4-1.0)^{*}$ & $105(7.2)$ & $0.78(0.6-1.0)$ \\
\hline \multicolumn{9}{|l|}{ Early-onset betel nut use ${ }^{d}$} \\
\hline No & $5,953(99.7)$ & $2,007(97.8)$ & $670(98.6)$ & 1.00 & $974(98.7)$ & 1.00 & $1,115(98.7)$ & 1.00 \\
\hline Y es & $21(0.3)$ & $62(2.2)$ & $14(1.4)$ & $0.61(0.3-1.4)$ & $18(1.3)$ & $0.59(0.3-1.3)$ & $24(1.3)$ & $0.57(0.3-1.0)^{*}$ \\
\hline \multicolumn{9}{|l|}{ A ge at first alcohol use } \\
\hline \multicolumn{9}{|l|}{ Less than once } \\
\hline per month & NA & $1,541(74.9)$ & $350(51.1)$ & 1.00 & $366(33.2)$ & 1.00 & $754(67.7)$ & 1.00 \\
\hline Once per month & & & & & & & & \\
\hline no & NA & $1,427(71.2)$ & $449(63.9)$ & 1.00 & $656(64.8)$ & 1.00 & $844(77.1)$ & 1.00 \\
\hline Yes & & $642(28.8)$ & $235(36.1)$ & $1.30(1.0-1.8)$ & $336(35.2)$ & $1.26(1.0-1.6)$ & $295(22.9)$ & $0.74(0.6-1.0) *$ \\
\hline
\end{tabular}

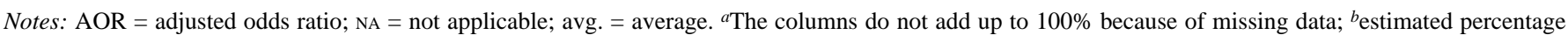
and odds ratios are derived based on complex survey analyses (weighted data with Taylor series linearization); cadjusted for age, male gender, school type, family structure, and weekly allowance; doccurred at the ages of primary-school $(<12)$; e used alcohol at least once in the preceding 30 days of assessment.

$* p<.05 ;{ }^{\dagger} p<.01 ; \ddagger^{\ddagger}<.001$. 

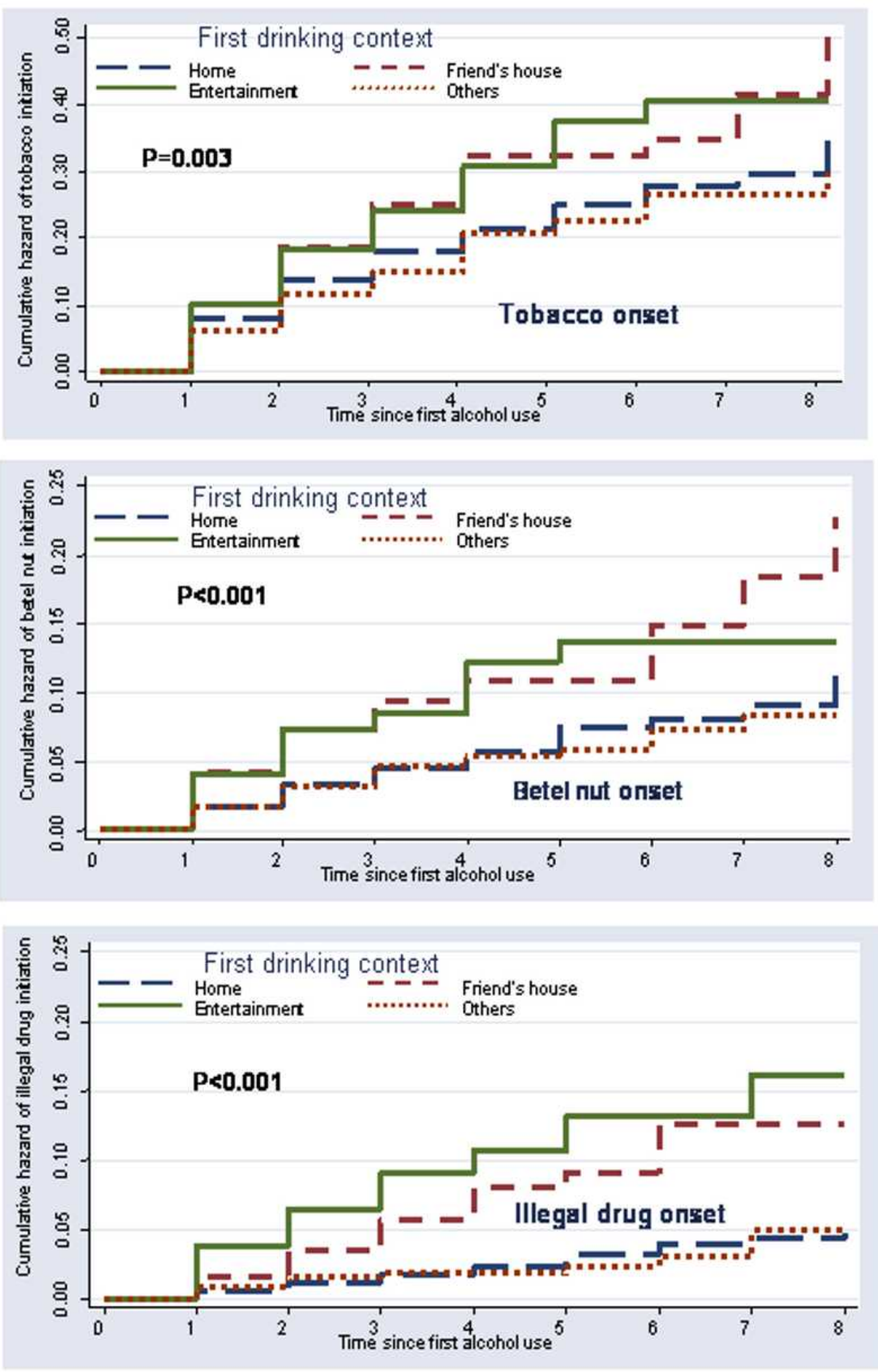

Figure 1. Cumulative hazard of tobacco, betel nut, and illegal drug initiation by first drinking context, with comparisons using the Wilcoxon (B reslow) test 
TABLE 3. Estimated hazard ratios (HRs) linking first drinking context to first use of tobacco, betel nut, and illegal drug, the 2004 National Survey of Illegal Drug Use among adolescents in Taiwan

\begin{tabular}{|c|c|c|c|}
\hline V ariables ${ }^{a}$ & $\begin{array}{c}\text { Tobacco } \\
\text { HR }(95 \% \mathrm{Cl})\end{array}$ & $\begin{array}{c}\text { B etel nut } \\
\text { HR }(95 \% \mathrm{Cl})\end{array}$ & $\begin{array}{l}\text { Illegal drug } \\
\text { HR }(95 \% \mathrm{Cl})\end{array}$ \\
\hline \multicolumn{4}{|l|}{ Crude } \\
\hline Friend's house $^{b}$ & $1.44(1.13-1.84)^{\dagger}$ & $1.99(1.40-2.84)^{\ddagger}$ & $3.11(2.02-4.79)^{\ddagger}$ \\
\hline Entertainment settings ${ }^{b}$ & $1.42(1.09-1.83)^{\dagger}$ & $1.98(1.43-2.74)^{\ddagger}$ & $5.21(3.51-7.74)^{\ddagger}$ \\
\hline Other settings ${ }^{b}$ & $0.85(0.68-1.06)$ & $0.90(0.62-1.30)$ & $1.09(0.63-1.86)$ \\
\hline$M$ ale gender & $1.78(1.45-2.18)^{\ddagger}$ & $5.69(3.16-8.97)^{\ddagger}$ & $1.73(1.08-2.77)^{*}$ \\
\hline Single-parent family & $1.43(1.11-1.84)^{\dagger}$ & $1.13(0.75-1.69)$ & $1.68(1.12-2.53)^{\dagger}$ \\
\hline W eekly allowance of $501-1,500$ & $1.35(1.14-1.59)^{\ddagger}$ & $1.88(1.40-2.53)^{\ddagger}$ & $2.30(1.64-3.22)^{\ddagger}$ \\
\hline W eekly allowance of 1,501 or above & $1.49(1.11-2.01)^{\dagger}$ & $2.11(1.38-3.23)^{\ddagger}$ & $2.72(1.68-4.41)^{\ddagger}$ \\
\hline Not living with family & $1.95(1.41-2.70)^{\ddagger}$ & $1.04(0.50-2.19)$ & $1.41(0.63-3.15)$ \\
\hline V ocational school attendance & $1.89(1.56-2.29)^{\ddagger}$ & $2.99(2.08-4.29)^{\ddagger}$ & $3.00(1.89-4.77)^{\ddagger}$ \\
\hline Runawayc & $2.99(2.41-3.71)^{\ddagger}$ & $2.86(2.05-3.98)^{\ddagger}$ & $6.95(5.03-9.61)^{\ddagger}$ \\
\hline Truancyc & $2.21(1.86-2.63)^{\ddagger}$ & $2.48(1.90-3.24)^{\ddagger}$ & $10.10(6.37-16.10)^{\ddagger}$ \\
\hline \multicolumn{4}{|l|}{ Model $1^{\mathrm{b}, \mathrm{d}}$} \\
\hline Friend's house & $1.12(0.86-1.45)$ & $1.34(0.97-1.86)$ & $1.73(1.07-2.78)^{*}$ \\
\hline Entertainment settings & $1.07(0.82-1.40)$ & $1.45(1.08-1.95)^{\ddagger}$ & $2.70(1.77-4.14)^{\ddagger}$ \\
\hline Other settings & $0.86(0.69-1.07)$ & $0.93(0.65-1.33)$ & $1.03(0.59-1.79)$ \\
\hline \multicolumn{4}{|l|}{ M odel $2^{b, d, e}$} \\
\hline Friend's house & $1.08(0.79-1.49)$ & $1.48(1.02-2.14)^{*}$ & $1.52(0.88-2.63)$ \\
\hline Entertainment settings & $0.96(0.70-1.33)$ & $1.50(1.08-2.07)^{\dagger}$ & $2.47(1.52-4.00)^{\ddagger}$ \\
\hline Other settings & $0.76(0.55-1.03)$ & $0.77(0.49-1.21)$ & $0.92(0.47-1.82)$ \\
\hline
\end{tabular}

Notes: $\mathrm{Cl}=$ confidence interval. ${ }^{a}$ Estimates were obtained from Cox proportional regression model taking school as clustering effects into account and with robust method of calculating the variance-covariance matrix; breference group: having the first drink at home; ctime-varying variables; dadjusted for listed covariates; eadjusted for covariates in M odel 1 in the subsample with alcohol initiation at age 12 years or above.

$* p<.05 ;{ }^{\dagger} p<.01 ;{ }^{\ddagger} p<.001$.

To probe possible gender-related differences in the risk of drug progression, we performed subsidiary analyses to compare gender-specific estimates of HRs. Taking illegal drug initiation as an example, for both genders, risk estimates linking family factors (e.g., single-parent family, living with family, allowance) were generally similar, and the first drinking situation-associated hazard risks were almost identical. Extra efforts were also made to introduce the product terms between gender and three family factors. No significant gender-associated moderational effects were found (data not shown).

In addition, to check the covariance patterns, a series of covariance matrix was estimated for each pair of confounding variables. In brief, the correlation ranged from .0018 (i.e., not living with family with type of high school) to .203 (i.e., early-onset tobacco use with early-onset betel nut use), with the corresponding covariance estimated from .000146 to .0047 . These subsidiary analyses suggested that most of the correlation estimates for pairs of ancillary variables were statistically significant, in terms of $p$ values less than .05. However, patterns of correlation and covariance indicated that the concern for multicollinearity should not pose a strong threat to the present analyses.

\section{Discussion}

In the cultural context that underage accessibility to alcoholic beverage is exceptionally easy, we have identified first drinking context-related differences in the progression from alcohol to betel nut and illegal drugs. On the basis of nationally representative high school students, our results show that more than $40 \%$ of the students had tried alcohol at least once in their lifetimes by age 15. Y outh who had their first drinks at social gatherings (i.e., entertainment settings and friends' houses) seem to consume alcohol more frequently in late adolescence. In addition, regardless of gender, family structure, weekly allowance, living status with family, type of school attendance, and prior experiences of running away from home and truancy, having their first al coholic beverage in entertainment settings (e.g., pub, karaoke lounges) was significantly associated with a faster onset of betel nut and illegal drugs.

Some potential limitations of this study should also be considered. The first limitation involves the specification of the survey population in relation to school-attending youth. As a result, these are limits when generalizing the present findings to non-school-based recruited samples, albeit the effort has been made to take truancy experiences into account by statistical adjustment. It is very likely that the observed estimates of HRs in this study may be lower than values derived from nonschool-attending individuals, given that the experiences of betel nut and illegal drug were more prevalent among dropouts and nonattendants (Chou et al., 2006; Gfroerer et al., 1997; Greene et al., 1997; Swaim et al., 1997). The second limitation in this study can be traced to its cross-sectional and nonexperimental 
design, which creates opportunities for errors in specification of temporal sequences (e.g., recall bias for initiation age or first drinking context). Prospective studies with frequent assessments may help overcome this limitation, and special efforts may also be needed to collect temporal order and time lag because two or more drugs have been experienced at the same reported age. Finally, because of the cultural, geographic, and societal differences, it might not be appropriate to generalize the observed association to other places with profiles of drug availability, drug diversity, and drug norms different from those of Taiwan.

Notwithstanding limitations such as these, the findings derived from this school survey with the nationally representative sample have offered new evidence on the factors accounting for a differential drug progression process from alcohol to other psychoactive drugs (i.e., betel nut and illegal drugs). Prior research suggests that there are particular progression patterns and sequences of drug involvement among adolescents that are heterogeneous across racial/ethnic group, birth cohort, gender, socioeconomic status, and age at first drug use (Golub and Johnson, 2001; Guerra et al., 2000; Novins et al., 2001). However, very few studies have explored possible roles of the first drinking context in the link between alcohol and subsequent illegal drug use. In addition, the large sample size of youth in mid-adolescence allows us to identify drinking context-related heterogeneity in higher frequency of alcohol consumption and faster progression of drug experiences in society, wherein the prevalence of illegal drug use is relatively uncommon compared with the ones in other W estern countries.

Within the cultural context wherein social norms are more tolerant, if not encouraging, of underage drinking, these results can be interpreted in one of several ways. First, the observed elevated risks of advanced alcohol involvement and earlier initiation of betel nut and illegal drugs among youth having their first drink in the contexts such as entertainment settings may be the result of mixed and reciprocal processes of differential drug availabilities, rising opportunities owing to social contagion, and differential association (Fergusson et al., 2006; Osgood et al., 1996; W eitzman et al., 2005). For example, for social contexts such as night clubs or karaoke lounges, accessibility to certain illegal drugs seems relatively easier compared with one's own home. It may be expected that adolescents who had their first drink in entertainment settings may spend a great amount of time within these environments, and, consequently, they have a greater chance of being exposed to drug-using adults and peers or even being offered drugs (Chen et al., 2004; W agner and A nthony, 2002).

A nother perspective that may account for this observed excess risk of illegal drug involvement associated with the first drink in socializing gatherings (e.g., friends' houses and entertainment settings) may be supported by the work of Orcutt (1975), suggesting that young adults' definitions for deviance (e.g., alcohol and marijuana use) were a context-dependent phenomenon. In keeping with this point of view, one's involvement with alcohol, tobacco, or marijuana seem much more acceptable if an individual was in the context of socio-emotional functions (e.g., social gathering) and social motivations (e.g., when the context demands mutual social participation in drug-related activities). Thus, youth who had their first drink in entertainment settings or at friends' houses might be inclined to the idea that psychoactive drug-using behaviors are acceptable or ordinary in situations with socio-emotional or sociomotivational functions. However, we cannot rule out that the observed differential risks in high-frequency alcohol consumption and the involvement of illegal drugs and betel nut may be, in part, the result of other unmeasured variables, such as parental monitoring/supervision, deviant peer affiliation, personality, or school neighborhood (Chilcoat and A nthony, 1996; M aes and Lievens, 2003). For example, it is possible that youth who had first drinks at places such as friends' houses or entertainment settings were more likely to be those having lower levels of parental monitoring/supervision, compared with their counterparts who had alcoholic beverages at family functions.

Our findings may also lend some empirical evidence to a broader range of health policies in Taiwan, such as improved implementation of minor protection law governing underage access to alcoholic beverages or alcohol use in public places (A guirre-M olina and Gorman, 1996; Wagenaar and Perry, 1994). Given that alcohol initiation in entertainment settings may be associated with a more rapid progression into the involvement of betel nut and illegal drugs, public health practices or prevention programs should give more emphasis to context or environmental settings associated with adolescent psychoactive drug use, including efforts to limit access and availability, expand alcohol- or tobacco-free entertainment settings, or encourage responsive entertainment/beverage services (A guirre-M olina and Gorman, 1996; Wagenaar and Perry, 1994; Weitzman et al., 2005). Finally, in the case that alcohol-experienced youth were uniformly more likely to experience other psychoactive drugs than their alcohol-naive counterparts, public health strategies are needed to target parents or families to address the issues such as minimal drinking age and harmful effects of underage drinking.

\section{Acknowledgments}

The authors thank M r. Po-Chang Hsiao of the Genetic Epidemiology Core L aboratory at National Taiwan University Center for Genomic M edicine for his help in the set-up of the survey database, and Drs. ChengFang $Y$ en, Chaucer C.H. Lin, M ing-Jen $Y$ ang, and Te-Jen Lai for their help in the conduction of the National Survey of Illegal Drug Use among A dolescents. 


\section{R eferences}

Achenbach, T.M. Manual for the Youth Self-Report and 1991 Profile, Burlington, VT: Department of Psychiatry, University of Vermont, 1995.

AdLeR, I. AND KANDEL, D.B. Cross-cultural perspectives on developmental stages in adolescent drug use. J. Stud. A lcohol 42: 701-715, 1981.

A guirre-Molina, M. And Gorman, D.M. Community-based approaches for the prevention of alcohol, tobacco, and other drug use. A nnual Rev. Publ. HIth 17: 337-358, 1996.

Bonnie, R.J. And O'Connell, M.E. (Eds.) Reducing Underage Drinking. A Collective Responsibility, Washington, DC: The National Academies Press, 2004.

Changrani, J. and Gany, F. Paan and Gutka in the United States: An emerging threat. J. Immigr. HIth 7: 103-108, 2005

Chen, C.Y., Chen, W.C., LeW-Ting, C.Y., Lee, C.M., Yen, C.F., Chen, D.R., HSIAO, C.K., LIN, C.C., YANG, M.J., LAI, T.J., AND CHEN, W.J. Employment experience in relation to alcohol, tobacco, and betel nut use among youth in Taiwan. Drug A Icohol Depend. 84: 273-280, 2006.

Chen, C.Y., Dormitzer, C.M., Gutierrez, U., Vittetoe, K., Gonzalez, G.B., And Anthony, J.C. The adolescent behavioral repertoire as a context for drug exposure: Behavioral autarcesis at play. Addiction 99: 897-906, 2004.

Chen, C.Y., Storr, C.L., Tang, G.-M., Huang, S.-L., Hsiao, C.K., And CHEN, W.J. Early alcohol experiences and adolescent mental health: A population-based study in Taiwan. Drug A Icohol Depend., 2008.

Chiang, S.C., Chen, S.J., Sun, H.J., Chan, H.Y., And Chen, W.J. Heroin use among youths incarcerated for illicit drug use: Psychosocial environment, substance use history, psychiatric comorbidity, and route of administration. A mer. J. A ddict. 15: 233-241, 2006.

Chilcoat, H.D. And Anthony, J.C. Impact of parent monitoring on initiation of drug use through late childhood. J. A mer. A cad. Child A dolesc. Psychiat. 35: 91-100, 1996.

Chou, L.C., Ho, C.Y., Chen, C.Y., And Chen, W.J. Truancy and illicit drug use among adolescents surveyed via street outreach. Addict. Behav. 31: 149-154, 2006.

$\mathrm{CHU}, \mathrm{N}$.S. Effects of Betel chewing on the central and autonomic nervous systems. J. Biomed. Sci. 8: 229-236, 2001.

Clapp, J.D., Shillington, A.M., and Segars, L.B. Deconstructing contexts of binge drinking among college students. A mer. J. Drug. Alcohol A buse 26: 139-154, 2000.

Cochrane, J., Chen, H., Conigrave, K.M., and Hao, W. Alcohol use in China. Alcohol Alcsm 38: 537-542, 2003.

Demers, A., Kairouz, S., Adlaf, E.M., Gliksman, L., Newton-Taylor, B., AND M ARCHAND, A. M ultilevel analysis of situational drinking among Canadian undergraduates. Social Sci. M ed. 55: 415-424, 2002.

Fergusson, D.M., Boden, J.M., And Horwood, L.J. Cannabis use and other illicit drug use: Testing the cannabis gateway hypothesis. Addiction 101: 556-569, 2006.

Grroerer, J., Wright, D., and Kopstein, A. Prevalence of youth substance use: The impact of methodological differences between two national surveys. Drug A Icohol Depend. 47: 19-30, 1997.

Golub, A. And Johnson, B.D. The shifting importance of alcohol and marijuana as gateway substances among serious drug abusers. J. Stud. Alcohol 55: 607-614, 1994.

GoLUB, A. AND JOHNSON, B.D. Variation in youthful risks of progression from alcohol and tobacco to marijuana and to hard drugs across generations. A mer. J. Publ. HIth 91: 225-232, 2001.

Greene, J.M., Ennett, S.T., and Ringwalt, C.L. Substance use among runaway and homeless youth in three national samples. A mer. J. Publ. HIth 87: 229-235, 1997.

Guerra, L.M., Romano, P.S., Samuels, S.J., and Kass, P.H. Ethnic differences in adolescent substance initiation sequences. Arch. Pediat. A dolesc. M ed. 154: 1089-1095, 2000.
HaO, W., Chen, H., And Su, Z. China: Alcohol today. Addiction 100: 737-741, 2005.

Harford, T.C., Wechsler, H., and Rohman, M. The structural context of college drinking. J. Stud. A lcohol 44: 722-732, 1983.

Kairouz, S., Gliksman, L., Demers, A., and Adlaf, E.M. For all these reasons, I do...drink: A multilevel analysis of contextual reasons for drinking among Canadian undergraduates. J. Stud. Alcohol 63: 600608, 2002.

KANDEL, D. Stages in adolescent involvement in drug use. Science 190: 912-914, 1975.

Kandel, D.B., Yamaguchi, K., and Chen, K. Stages of progression in drug involvement from adolescence to adulthood: Further evidence for the gateway theory. J. Stud. A lcohol 53: 447-457, 1992.

KNIBbE, R. M easuring drinking context. Alcsm Clin. Exp. Res. 22 (2 Suppl.): S15-S20, 1998.

Lee, E.S. and Forthofer, R.N. A nalyzing Complex Survey Data, Thousand Oaks, CA: Sage, 2005.

Lin, M.R., Chang, S.H., PAI, L., And KeYL, P.M. A longitudinal study of risk factors for motorcycle crashes among junior college students in Taiwan. Accid. A nal. Prev. 35: 243-252, 2003.

Maes, L. And Lievens, J. Can the school make a difference? A multilevel analysis of adolescent risk and health behaviour. Social Sci. M ed. 56: 517-529, 2003.

Novins, D.K., BeAls, J., ANd M ITChell, C.M. Sequences of substance use among A merican Indian adolescents. J. A mer. A cad. Child A dolesc. Psychiat. 40: 1168-1174, 2001.

O'M ALley, P.M., JOHnSton, L.D., ANd Bachman, J.G. Alcohol use among adolescents. Alcohol HIth Res. World 22: 85-93, 1998.

ORCUTt, J.O. Deviance as a situated phenomenon: $V$ ariations in the social interpretation of marijuana and alcohol use. Social Probl. 22: 346-356, 1975.

Osgood, D.W., Wilson, J.K., O'Malley, P.M., Bachman, J.G., and JOHNSTON, L.D. Routine activities and individual deviant behavior. A mer. Social. Rev. 61: 635-655, 1996.

Rossow, I. Alcohol-related violence: The impact of drinking pattern and drinking context. Addiction 91: 1651-1661, 1996.

ShORE, J.H. AND SPICER, P. A model for alcohol-mediated violence in an A ustralian A boriginal community. Social Sci. Med. 58: 2509-2521, 2004.

So, D.W., Wong, F.Y., and Deleon, J.M. Sex, HIV risks, and substance use among A sian A merican college students. AIDS Educ. Prev. 17: 457-468, 2005.

Swaim, R.C., Beauvais, F., Chavez, E.L., and Oetting, E.R. The effect of school dropout rates on estimates of adolescent substance use among three racial/ethnic groups. A mer. J. Publ. HIth 87: 51-55, 1997.

Wagenaar, A.C. And Perry, C.L. Community strategies for the reduction of youth drinking: Theory and application. J. Res. Adolesc. 4: 319345, 1994

Wagner, F.A. and Anthony, J.C. Into the world of illegal drug use: Exposure opportunity and other mechanisms linking the use of alcohol, tobacco, marijuana, and cocaine. A mer. J. E pidemiol. 155: 918-925, 2002.

Warner, L.A. AND White, H.R. Longitudinal effects of age at onset and first drinking situations on problem drinking. Subst. Use M isuse 38: 1983-2016, 2003.

Weitzman, E.R., Chen, Y.Y., and Subramanian, S.V. Y outh smoking risk and community patterns of alcohol availability and control: A national multilevel study. J. Epidemiol. Commun. HIth 59: 1065-1071, 2005.

Wen, C.P., Cheng, T.Y., ERiksen, M.P., Tsal, S.P., and Hsu, C.C. The impact of the cigarette market opening in Taiwan. Tob. Control $\mathbf{1 4}$ (Suppl. N o. 1): i4-i9, 2005a.

Wen, C.P., Tsal, S.P., Cheng, T.Y., Chen, C.J., Levy, D.T., Yang, H.J., AND ERIKSEN, M.P. Uncovering the relation between betel quid chewing and cigarette smoking in Taiwan. Tob. Control 14 (Suppl. No. 1): i16-i22, 2005b. 
Y ANG, M.J. The Chinese drinking problem: A review of the literature and its implication in a cross-cultural study. Kaohsiung J. Med. Sci. 18: 543-550, 2002.
Yen, C.F., Hsu, S.Y., ANd Cheng, C.P. Polysubstance use and its correlates in adolescent ecstasy users in Taiwan. Addict. B ehav. 32: 22862291, 2007. 